\title{
Pemberdayaan Masyarakat Desa dalam Pengembangan Ekonomi Digital kepada Industri Kecil dalam Menghadapi Covid-19 di Desa Mentaren II Pulang Pisau
}

\section{Empowerment of Village Communities in Digital Economy Development to Small Industries in Facing Covid-19 in Mentaren II Village, Pulang Pisau}

\author{
Indah Tri Handayani* \\ Bahrianoor \\ Department \\ of Public \\ Admininstration, Universitas
Muhammadiyah \\ Palangka Raya, Central Kalimantan, \\ Indonesia
}

email: indahdishub25@gmail.com

\section{Kata Kunci}

Ekonomi digital

Pemberdayaan

Pengembangan

Keywords:

Digital economy

Empowerment

Development

Received: December 2020

Accepted: February 2021

Published: April 2021

\begin{abstract}
Abstrak
Desa Mentaren II merupakan desa produktif sebagai sentral industri pengolah makanan ringan, dimana mayoritas masyarakatnya memanfaatkan lahan pertanian sebagai mata pencaharian untuk dijadikan berbagai pengolaan makanan ringan. Pengelolaan Industri kecil di desa ini sudah berlangsung sejak lama, para pelaku usaha memiliki bahan dan peralatan masing-masing dalam praktek pengeolahannya. Pukades ini termasuk salah satu program unggulan desa dalam arah pembangunan di desa. Dengan adanya produk unggulan desa ini diharapkan dapat mendongkrak peluang kerja yang ada di pedesaan. Sehingga secara sistematik, mampu untuk meningkatkan daya beli dan mengurangi tingkat kemiskinan di desa. Prospek penjualannya cukup berkembang, dibuktikan dengan banyaknya hasil pengelohan mereka diperdagangkan di warung pinggiran sepanjang jalan lintas Kalimantan, bahkan langsung dengan pembeli. Akan tetapi pengembangan industri ini mendapat kendala semenjak pendemi covid-19 yang mengharuskan masyarakat tidak bekerumun. Hal ini berdampak terutama pada pelaku usaha yang selama ini mengandalkan sistem pemasaran konvensional. Pada tahapan ini tim pengabdian berkunjung ke kantor desa dan bertemu kepala desa beserta perangkat desa, berdiskusi terkait keaktifan kelembagaan desa baik BUMDes maupun Posyantek yang ada di desa. Tim pengabdi langsung terjun kelapangan dengan mengunjungi kebeberapa lokasi rumah yang memiliki usaha dan melakukan interview singkat terhadap prosesi pengelolaan kegiatan dan berbagai Kendala.
\end{abstract}

\begin{abstract}
The village of Mentaren II is productive as the center of the snack processing industry. The majority of the people use agricultural land as a livelihood to make various snacks. The management of small industries in this village has been going on for a long time; business actors have their own materials and equipment in their processing practices. Pukades is one of the leading village programs in the direction of development in the village. With this superior village product, it is hoped that it can boost job opportunities in the countryside. So that systematically, it can increase purchasing power and reduce the level of poverty in the village. The sales prospect is quite developed, as evidenced by the many results of their complaining that they are traded in suburban stalls along the Kalimantan road, even directly with buyers. However, this industry's development has faced obstacles since the Covid-19 epidemic, which requires the public not to gather together. This has an impact, especially on business actors who have been relying on conventional marketing systems. At this stage, the community service team visits the village office and meets the village head and village officials, discussing village institutions' activeness, both BUMDes, and Posyantek, in the village. The service team immediately went into the field by visiting several houses that had businesses and conducting brief interviews with the procession of managing activities
\end{abstract} and various obstacles. 


\section{PENDAHULUAN}

Penetapan kebijakan pembangunan desa pada UndangUndang Nomor 6 Tahun 2014 Tentang Desa adalah upaya peningkatan kualitas hidup dan kehidupan untuk meraih kesejahteraan masyarakat desa melalui otonomi desa. Pembangunan desa berdasarkan dari amanah UU Desa tersebut mengharuskan pada upaya peningkatan kesejahteraan masyarakat desa dan kualitas hidup manusia melalui kegiatan pelayanan sosial dasar, pemberdayaan masyarakat desa, pembangunan sarana dan prasarna desa, pengembangan potensi ekonomi lokal, dan pemanfaatan sumberdaya alam serta lingkungan secara berkelanjutan (Rahmasari, 2020; Lailasari et al., 2017).

Inisiasi desa dalam upaya mengembangkan keberdayaan pada bidang ekonomi mulai dilakukan, penciptaan kegiatan-kegiatan yang membuka akses produksi, distribusi, dan pasar bagi usaha dalam pengelolaan kolektif maupun individu berlahan mulai berkembang (Pohan, 2016). Salah satunya adalah berkembangnya industri kecil dari pemanfaatan produk unggulan yang dimiliki desa. Hal yang mendasari berkembang industri kecil tersebut adalah karena adanya semangat kewirausahaan masyarakat lokal (Azizah \& Muhfiatun, 2017).

Sejauh ini industri kecil telah diproduksi dengan kuantitas dan kualitas yang cukup baik. Namun, para pelaku usaha masih menemui kendala terutama minimnya pengetahuan tentang pemanfaatan informasi dan teknologi melalui digitalisasi seperti menggunakan media sosial untuk memasarkan produksinya (Awali \& Rohmah, 2020; Arianto, 2020). Seperti halnya Desa Mentaren II, desa ini merupakan desa produktif sebagai sentral industri pengolah makanan ringan, dimana mayoritas masyarakatnya masih memanfaatkan lahan pertanian sebagai mata pencaharian untuk dijadikan berbagai pengolahan makanan ringan.
Pengelolaan industri kecil di desa ini sudah berlangsung sejak lama, para pelaku usaha memiliki bahan dan peralatan masing-masing dalam praktek pengeolahannya. Prospek penjualannya cukup berkembang, hal ini dibuktikan dengan banyaknya hasil pengolahan mereka di perdagangkan di warungwarung pinggiran sepanjang jalan lintas Kalimantan, bahkan langsung dengan pembeli. Akan tetapi pengembangan industri kecil ini mendapat kendala, terlebih semenjak pendemi covid-19 yang mengharuskan masyarakat tidak berkerumun. Hal ini berdampak terutama pada pelaku usaha yang selama ini hanya sistem pemasaran konvensional, yakni melalui pasar dadakan tradisional disetiap desa atau bertemu langsung dengan pembeli (Febryantoro \& Arisandi, 2018; Handajani et al., 2019).

Kendala tersebut tentunya dapat diatasi dengan kegiatan ekonomi berbasis digital yaitu melalui media sosial seperti WhatsApp, Facebook, Instagram dan juga Shopee yang dapat menfasilitasi pemasaran melalui jaringan informasi modern sebagai ruang aktivitas yang penting (Sulaksono \& Zakaria, 2020). Misalkan memanfaatkan kekuatan media sosial dan internet sebagai media pemasaran untuk menjangkau konsumen (Moriansyah, 2015). Untuk itulah pengabdian kepada masyarakat kali ini mencoba mengenalkan dengan melakukan pendekatan pemberdayaan tentang pengatahuan masyarakat Desa Mentaren II terhadap digitalisasi ekonomi dengan memperkenalkan media sosial untuk sarana pemasaran mereka nantinya.

\section{METODOLOGI}

Metode yang dipakai dalam upaya mencapai tujuan pengabdian ini adalah melalui beberapa cara yaitu:

1. Metode sosialisasi, bertujuan untuk memberikan pemahaman arti pentingnya pengembangan ekonomi berbasis digital, dalam era digital sekarang 
sangat membantu pengembangan kehidupan sosial, budaya, dan ekonomi masyarakat, terutama dimasa pandemi covid-19 ini.

2. Metode pelatihan, bertujuan untuk meningkatkan pengetahuan dan keterampilan para pelaku usaha dalam pembuatan media sosial yang akan membantu memasarkan hasil usahanya

3. Praktek lapangan, yakni praktek cara mengambilan gambar dengan handphone masing-masing pelaku usaha agar menarik sehingga bisa masuk di akun di media sosial, dan cara menarasikan penawaran.

4. Metode pemantauan, yakni melaksanakan pemantauan hasil pelatihan yang diberikan dengan bekerja sama dengan pihak lembaga desa dan pembina usaha desa sejauh mana hasil usaha mereka yang dipasarkan melalui media sosial.

Selanjutnya konsultasi, yang bertujuan untuk memberikan kesempatan kepada masyarakat dalam menyampaikan hambatan, tantangan, maupun kendala saat melakukan tindak lanjut dari pengembangan ekonomi, sehingga diharapkan mendapat solusi yang proporsional. Konsultasi ini dilakukan dengan media interaksi berupa SMS/WhatsApp, telepon, Zoom Meeting, atau media virtual lainnya dari masyarakat dengan tim pengabdi untuk melakukan monitoring. Targetnya penguatan kompetensi para pelaku usaha dalam memanfaatkan media sosial secara mendalam.

\section{HASIL DAN PEMBAHASAN}

Kegiatan pengabdian kepada masyarakat ini bertujuan untuk memberikan pelatihan dan pendampingan kepada para pelaku usaha kecil dan meliputi tahapantahapan sebagai berikut:

\section{Persiapan}

Tahap ini dilakukan sebelum pelaksanaan PKM, yaitu Rapat Persiapan Perencanaan, melakukan koordinasi internal tim pelaksana, membuat rencana pelaksanaan berupa jadwal dan tempat pelaksanaan. Pembuatan instrumen PKM, seperti lembar presensi, lembar kerja, penyusunan modul bahan sosialisasi dan pelatihan, dan persiapan bahan sosialisasi dan pelatihan, serta dokumentasi. Selanjutnya Koordinasi dengan Mitra yaitu Pihak perangkat Desa Mentaren II Kabupaten Pulang Pisau, menemui langsung Kepala Desa Mentaren II Kabupaten Pulang Pisau dan memohon fasilitasi tempat kegiatan dan jumlah warga Desa Mentaren II yang kelompok-kelompok masyarakat desa yang memiliki usaha industri kecil untuk menjadi peserta kegiatan.

\section{Pelaksanaan}

Pelaksanaan kegiatan dimulai dengan pembukaan dan yang dibuka oleh ibu Sekrertaris Desa Mentaren II Kabupaten Pulang Pisau dan dilanjutkan sosialisi kepada pelaku usaha yang ada di Desa Mentaren II untuk penguatan kompetensi para pelaku usaha dalam memanfaatkan media sosial yang seperti WhatsApp, Facebook, Instagram dan dilanjutkan dengan pelatihan membuat media sosial untuk para pelaku usaha dan praktek cara untuk mebuat foto dan video produk yang akan dijual agar terlihat menarik pembeli. Dokumentasi kegiatan yang dilaksanakan disajikan pada Gambar 1 dan 2.

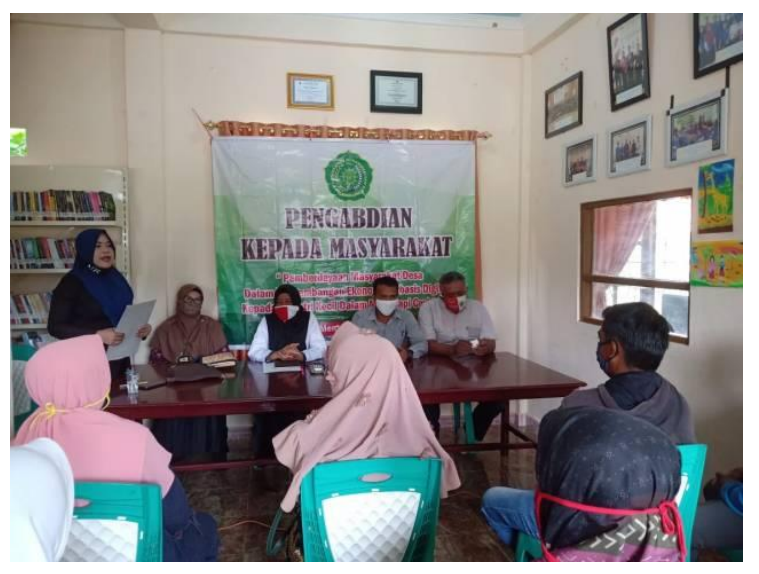

Gambar 1. Pembukaan kegiatan pengabdian 


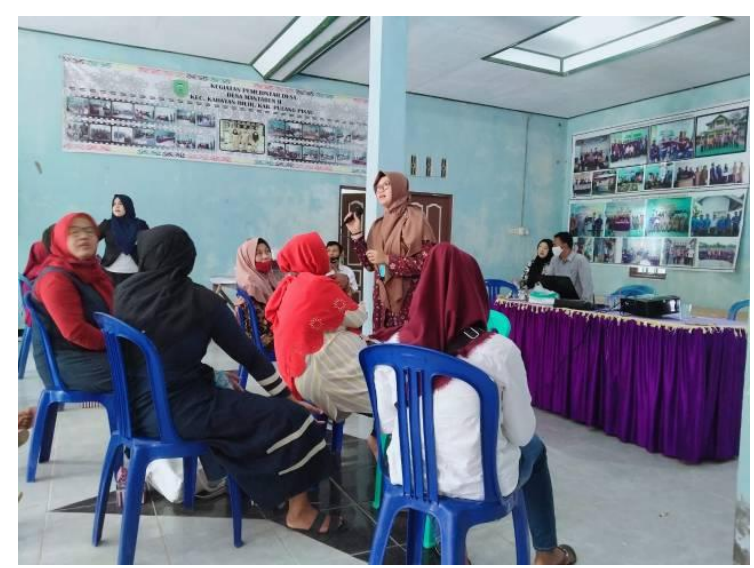

Gambar 2. Penyampaian materi oleh tim pengabdian

\section{Monitoring dan evaluasi}

Setelah pelaksanaan edukasi, selanjutnya dilakukan monitoring dan evaluasi terdiri dari hasil kegiatan berupa tercapainya target jumlah peserta yang mengikuti Kegiatan Pengabdian Kepada Masyarakat sebanyak 26 orang yang terdiri dari pelaku usaha kecil di Desa Mentaren II dari pelaku usaha pertanian, makanan, dan kerajinan.

Indikator lain berupa tersampaikannya materimateri kegiatan kepada peserta diantaranya materi tentang digitalisasi ekonomi desa yang didalam materi disampaikan bahwa memberikan pemahaman arti pentingnya pengembangan ekonomi berbasis digital, dalam era digital sekarang sangat membatu pengembangan kehidpan sosial, budaya, dan ekonomi masyarakat, terutama dimasa pandemi covid-19 ini dan didalam pelatihan ini banyak pengetahuan dan keterampilan yang didapatkan para pelaku usaha dalam pembuatan media sosial yang akan membantu memasarkan hasil usaha nya. Melalui Praktek lapangan yakni praktek cara pengambilan gambar memakai handphone masing-masing pelaku usaha biar menarik sehingga bisa masuk di akun dimedia sosial, dan cara menarasikan penawaran agar menarik para pembeli. terbentuknya komunitas pelaku usaha melalui media online WhatsApp lalu melakukan pemantauan yakni melaksanakan pemantauan hasil pelatihan yang diberikan dengan bekerja sama dengan pihak lembaga desa dan pembina usaha desa sejauh mana hasil usaha mereka yang dipasarkan memalui media sosial dan para pelaku usaha sudah mengaplikasikan kegiatan yang dilaksanakan dengan berjualan melalui media sosial seperti Facebook dan WhatsApp.

Selain itu juga dilakukan publikasi kegiatan melalui media sosial dengan tautan berikut:

a. Betang TV: https://betang.tv/di-desaMentaren-ii-dosen-fisip-um-palangka-rayagelar-pengmas/

b. Metro Kalimantan: https://www.metrokalimantan.com/2020/09/ pengmas-fisip-ump-beri-arahan-inike.html?m=1

\section{KESIMPULAN}

Berdasarkan hasil dan serangkaian kegiatan yang sudah dilakukan seperti tersebut di atas maka dapat diambil kesimpulan bahwa semua tahapan kegiatan pelatihan mulai dari penjelasan materi dapat dipahami dengan baik. Hal ini bisa dibuktikan ketika pelaksanaan dapat dilakukan dengan baik oleh seluruh peserta dengan hasil yang cukup memuaskan. Seluruh peserta menyatakan diri bahwa mereka sangat antusias dalam mengikuti kegiatan sosialisasi dan pelatihan sasaran kepada kelompok-kelompok masyarakat desa yang memiliki usaha industri kecil, berkontribusi dalam Pengembangan ekonomi digital harus dimulai dari pemahaman pemerintah desa (Kepala Desa) tentang manfaat dan tujuan digitalisasi perekonomian desa. produk unggulan kawasan perdesaan karena para pemuda-pemuda desa yang memiliki minat kepada dunia online marketing, karena potensi pemuda untuk membangun desa merupakan modal yang sangat besar 
sehingga merasa materi sangat bermanfaat menambah pengetahuan mereka, selain itu komunitas yang dibentuk akan mulai aktif dalam tahapan pelatihan pelatihan selanjutnya dan dapat berkembang.

\section{UCAPAN TERIMA KASIH}

Terima kasih kepada LP2M Universitas Muhammadiyah Palangkaraya yang telah mendanai kegiatan pengabdian tahun ini.

\section{REFERENSI}

Arianto, B. 2020. Pengembangan UMKM Digital di Masa Pandemi Covid-19. ATRABIS: Jurnal Administrasi Bisnis. 6(2):233-247. https://doi.org/10.38204/atrabis.v6i2.512

Awali, H., Rohmah, F. 2020. Urgensi Pemanfaatan EMarketing pada Keberlangsungan UMKM di Kota Pekalongan di Tengah Dampak COVID19. Balanca: Jurnal Ekonomi dan Bisnis Islam. 2(1):1-14. https://doi.org/10.35905/balanca.v2i1.1342

Azizah, S.N., Muhfiatun, M. 2017. Pengembangan Ekonomi Kreatif Berbasis Kearifan Lokal Pandanus Handicraft dalam Menghadapi Pasar Modern Perspektif Ekonomi Syariah (Study Case di Pandanus Nusa Sambisari Yogyakarta). Aplikasia: Jurnal Aplikasi Ilmu-Ilmu Agama. 17(2):63-78. https://doi.org/10.14421/aplikasia.v17i2.127 3

Febriyantoro, M.T., Arisandi, D. 2018. Pemanfaatan Digital Marketing Bagi Usaha Mikro, Kecil Dan Menengah Pada Era Masyarakat Ekonomi Asean. Jurnal Riset Manajemen dan Bisnis Dewantara (JMD). 1(2):62-76. https://doi.org/10.26533/jmd.v1i2.175

Handajani, L., Akram, Furkan, L.M., Rifa'i, A. 2019. Penggunaan Pemasaran Digital pada Usaha Home Industry Kopi Lombok di Desa Sigerongan Kabupaten Lombok Barat. Jurnal Abdi Insani Universitas Mataram. 6(3):409-421. https://doi.org/10.29303/abdiinsani.v6i3.267

Lailasari, S., Sumpena, D., Aliyudin. 2017. Pemberdayaan Masyarakat dalam Upaya
Peningkatan Kesejahteraan Keluarga Melalui Budidaya Ikan. Tamkin: Jurnal Pengembangan Masyarakat Islam. 2(1):77-95.

Moriansyah, L. 2015. Pemasaran Melalui Media Sosial: Antecedents dan Consequences. Jurnal Penelitian Komunikasi dan Opini Publik. 19(3):187-196.

http://dx.doi.org/10.33299/jpkop.19.3.346

Pohan, S.S. 2016. Pengaruh Produktivitas Petani Dan Distribusi Hasil Pertanian/Kebun Terhadap Pemasarannya Di Pasar Karanggede Kabupaten Boyolali Jawa Tengah. Value Added: Majalah Ekonomi dan Bisnis. 12(1):67-84.

Rahmasari, B. 2020. Pengelolaan Keuangan Desa Ditinjau dari Undang-Undang Desa Menuju Masyarakat yang Mandiri. Lex Renaissance. 5(2):488-507.

https://doi.org/10.20885/JLR.vol5.iss2.art15

Sulaksono, J., Zakaria, N. 2020. Peranan Digital Marketing Bagi Usaha Mikro, Kecil, Dan Menengah (UMKM) Desa Tales Kabupaten Kediri. Generation Journal. 4(1):41-48. https://doi.org/10.29407/gj.v4i1.13906 